NBER WORKING PAPER SERIES

\title{
THE EFFECT OF MEDICAID PAYMENT RATES ON ACCESS TO DENTAL CARE AMONG CHILDREN
}

Thomas C. Buchmueller

Sean Orzol

Lara D. Shore-Sheppard

Working Paper 19218

http://www.nber.org/papers/w19218

\author{
NATIONAL BUREAU OF ECONOMIC RESEARCH \\ 1050 Massachusetts Avenue \\ Cambridge, MA 02138 \\ July 2013
}

We are grateful for funding from the Robert Wood Johnson Foundation Health Care Financing and Organization and State Health Access Reform Evaluation initiatives and the National Science Foundation. Parts of this paper were written while Shore-Sheppard was visiting the Industrial Relations Section at Princeton University, and she is grateful for their hospitality and support. Caroline Chiappetti, Erik Levinsohn and Joel Segel provided excellent research assistance. Sandy Decker and seminar participants at BU, Carnegie Mellon, Duke, Iowa State, Vanderbilt and the OECD provided useful comments and suggestions. The usual disclaimer applies. The views expressed herein are those of the authors and do not necessarily reflect the views of the National Bureau of Economic Research.

NBER working papers are circulated for discussion and comment purposes. They have not been peerreviewed or been subject to the review by the NBER Board of Directors that accompanies official NBER publications.

(C) 2013 by Thomas C. Buchmueller, Sean Orzol, and Lara D. Shore-Sheppard. All rights reserved. Short sections of text, not to exceed two paragraphs, may be quoted without explicit permission provided that full credit, including $(\mathcal{C}$ notice, is given to the source. 
The Effect of Medicaid Payment Rates on Access to Dental Care Among Children

Thomas C. Buchmueller, Sean Orzol, and Lara D. Shore-Sheppard

NBER Working Paper No. 19218

July 2013

JEL No. H42,I13,I18

\begin{abstract}
$\underline{\text { ABSTRACT }}$
Historically, low Medicaid reimbursement rates have limited the willingness of health care providers to accept Medicaid patients, leading to access problems in many communities. This problem has been especially acute in the case of dental care. We combine data from several sources to examine the effect of payment rates on access to dental care among children on Medicaid and on dentists' participation in the program. The main utilization analysis is based on data from the Survey of Income and Program Participation combined with data on Medicaid payment rates and private market dental fees for the years 2001 to 2010. Conditioning on state fixed effects, we find a modest, but statistically significant, positive relationship between Medicaid payment rates and several measures of dental care utilization. We find a comparable effect in aggregate data reported by state Medicaid programs. The most likely explanation for this result is that higher fees increase the number of dentists that accept Medicaid patients. We test this hypothesis directly using data from annual surveys of dentists conducted by the American Dental Association between 1999 and 2009. The results indicate a positive and statistically significant effect of Medicaid payment rates on whether a dentist treats any publicly insured patients and the percent of the practice's patients who have public insurance. Similar to the utilization results, the magnitude of the effect is relatively small. As a result, the estimates imply that increasing Medicaid payments to the level of private market fees would increase access to care, but the incremental cost of the additional visits induced would be very high.
\end{abstract}

Thomas C. Buchmueller

Stephen M. Ross School of Business

University of Michigan

701 Tappan

Ann Arbor, MI 48109

and NBER

tbuch@umich.edu

\section{Sean Orzol}

Mathematica Policy Research

220 E. Huron Street, Suite 300

Ann Arbor, MI 48104-1912

sorzol@mathematica-mpr.com
Lara D. Shore-Sheppard

Department of Economics

Williams College

24 Hopkins Hall Drive

Williamstown, MA 01267

and NBER

1shore@williams.edu 


\section{Introduction}

Over the past two decades, increases in income eligibility limits for Medicaid and the establishment of the State Children's Health Insurance Program (CHIP) have resulted in significant increases in the number of American children covered by public health insurance. In 2011, more than a third of all children under age 18 were enrolled in Medicaid or CHIP (DeNavas-Walt et al. 2012). The Affordable Care Act (ACA) will continue the expansion of public insurance by permitting states to extend Medicaid eligibility to all persons with family incomes up to 138 percent of the Federal poverty level (FPL).

A fundamental goal of expanding public insurance coverage is to improve access to health care for low-income families. This will only occur if there is a sufficient supply of health care providers willing to treat publicly insured patients. Historically, low Medicaid reimbursement rates have limited provider participation, leading in turn to access problems in many communities. For this reason, the ACA not only expands eligibility for public coverage but also provides Federal funding to increase Medicaid reimbursement rates for primary care. However, this funding will be available only for two years, after which states will have to decide whether to use their own funds to maintain the higher rates. To understand the potential impact of this element of health care reform and to guide state decisions, it is important to understand how reimbursement policy affects the supply of services to Medicaid patients.

Low reimbursement rates are a particular concern in the case of dental care and are commonly cited as a primary reason that poor children have poor access to care and high rates of tooth decay (United States General Accounting Office (GAO) 2000b). The American Dental Association (ADA) has long advocated for increases in Medicaid rates as a primary strategy for improving access by increasing the participation of private practice dentists in Medicaid (Grover 
2008). The problem of low provider participation led to a number of class action lawsuits in the mid-1990s and early 2000s (Perkins 2007). In these lawsuits, advocates for low-income children and providers argued that inadequate reimbursement rates prevented children from receiving the Medicaid benefits to which they were entitled. In response to this legal pressure, a number of states increased payment rates for dental care. However, Medicaid dental reimbursement remains low in many states, causing access problems to persist. This issue was highlighted in 2007 by the tragic case of Deamonte Driver, a 12 year-old boy who died when an untreated infection from an abscessed tooth spread to his brain.

This paper examines the effect of Medicaid reimbursement on low-income children's access to dental care. Our analysis exploits cross-state variation in the timing and the magnitude of fee changes to estimate the effect of Medicaid payment rates on access to dental care for publicly insured children. Our main analysis is based on data from three panels of the nationally representative Survey of Income and Program Participation (SIPP) spanning the period 20012010, combined with hand-collected state level data on Medicaid dental payment rates for 15 common procedures. Using these data we estimate the relationship between Medicaid fees and three measures of dental care utilization: whether a child has had at least one visit over a 12 month period, the total number of visits during that period, and whether a child has had dental sealants applied.

Our results are consistent with the hypothesis that higher Medicaid payment rates improve access to dental care for publicly insured patients. We find a positive and statistically significant relationship between a state's Medicaid dental fees and the probability that a child covered by Medicaid has at least one dental visit over a 12-month period. Our estimates imply that a $\$ 10$ increase in the payment rate for an office visit leads to a 1.3-percentage point increase 
in the probability of an annual dental visit and that setting Medicaid rates equal to mean private market fees would close roughly two-thirds of the regression-adjusted gap in utilization between privately insured and publicly insured children. We also find a positive relationship between Medicaid payment levels and the number of dental visits in a year and the probability that a child received dental sealants. The results are robust to the use of different fee variables and to whether we measure Medicaid fees in constant dollars or relative to the mean fees charged to private payers.

A plausible explanation for these results is that the higher payment rates increase the willingness of private practice dentists to treat Medicaid patients. We directly test for this supply response using repeated cross-section data from the ADA's annual Survey of Dental Practice (SDP) covering the years 1999 to 2009. Regression results from these data confirm that changes in Medicaid dental payment rates are positively correlated with changes in the percentage of dentists that treat any Medicaid patients and the mean share of dentists' patients that are covered by Medicaid.

Using the results from the utilization analysis we calculate a rough estimate of the cost to Medicaid of the additional visits induced by raising payment rates. The implied cost per additional visit is roughly 8 times the amount of the current Medicaid payment rate. The high cost derives from the fact that increased fees have a relatively small effect on utilization. As a result, when states raise Medicaid payments, the vast majority of the increase in spending goes for visits that would have occurred at the lower fee level. 


\section{Background and Previous Literature}

\section{Medicaid and Dental Care}

Tooth decay is the most common chronic disease among children and there are large income-related disparities in access to dental care (Newacheck et al. 2000; U.S. Department of Health and Human Services 2000, hereafter DHHS 2000). Consequently, low-income children have significantly elevated rates of untreated caries and other dental problems (United States GAO 2000a; Mouradian et al., 2000). In the short run, untreated caries can lead to pain, which makes it difficult for children to eat, play and learn (Gift et al. 1992). Longer-term consequences include tooth loss, gum disease and related complications (DHHS 2000). Research has also found a connection between periodontal infections and serious medical conditions, including diabetes, heart disease and stroke (Fisher-Owens et al. 2008). In addition to these health issues, evidence from recent research suggests that dental problems negatively impact labor market success, presumably because of the effect of bad teeth on a worker's appearance (Glied and Neidell 2010).

As dental diseases are both treatable and preventable, public health insurance has the potential to reduce disparities in dental care and improve the dental health of low-income children. Dental care is included in the Early and Periodic Screening, Diagnostic, and Treatment (EPSDT) services that must be covered by the Medicaid program. States are required to cover dental services "provided at intervals that meet reasonable standards of dental practice" and "at a minimum include relief of pain and infections, restoration of teeth, and maintenance of dental health" (Centers for Medicare and Medicaid Services 2004). The regulations call for states to consult with recognized dental organizations, such as the state dental society, in determining the intervals for regular dental visits. The American Academy of Pediatric Dentistry (AAPD) 
recommends that children have a dental examination following the eruption of the first tooth and no later than 12 months of age. After that, the AAPD recommends semi-annual dental visits (AAPD 2009).

Utilization of dental services by children on Medicaid typically falls considerably short of these recommendations. Prior research has shown that children with Medicaid coverage are more likely to have periodic dental visits than children who are uninsured, though they have significantly fewer visits than children with private dental insurance (Manski et al. 2001; Manski et al. 2002; Sohn et al. 2007). Similarly, children with Medicaid are more likely to report unmet dental needs than children with private dental coverage (Kenney et al. 2005). A primary reason for this access problem is limited dentist participation in Medicaid (United States GAO 2000b, 2010). The main reason that dentists give to explain their low participation rates is the low level of reimbursement. ${ }^{1}$

\section{Economic Theory and Previous Empirical Research}

A starting point for considering the effect of Medicaid fees on access to care is a simple model of a profit-maximizing health care provider who allocates supply between private and public patients (Sloan et al. 1978). Assuming the provider faces a downward-sloping demand curve for private patients and that the cost of providing care is the same for both types, the optimal allocation will be one where the marginal revenue from private patients equals the fixed Medicaid payment rate and the provider's marginal cost. ${ }^{2}$ A main prediction of this model is that when Medicaid rates rise relative to private market fees, a greater number of providers will see

\footnotetext{
${ }^{1}$ Other reasons given include burdensome administrative requirements and the fact that Medicaid patients are less likely than commercial patients to keep appointments and comply with treatment regimens (Damiano et al. 1990).

${ }^{2}$ The cost of treating public patients may be higher if, for example, they are more likely to miss appointments or if there are higher administrative costs associated with billing Medicaid.
} 
any public patients and those that treat a mix of public and private patients will treat a greater number of public patients.

The extent to which higher Medicaid payments translate to greater overall utilization of care among Medicaid patients will depend on the availability of other sources of care. If when Medicaid rates are low program enrollees receive care in a public health clinic, the main effect of increasing Medicaid rates may be to shift the site of care from those clinics to private practices, with little effect on total utilization. On the other hand, if publicly insured patients do not have good alternatives to private providers, low payment rates will inhibit access to care, and a rise in public program payment rates will lead to an increase in utilization.

Several studies find a positive relationship between Medicaid reimbursement and physician participation in the program. Using data from a cross-sectional survey of physicians, Sloan et al. (1978) find that higher Medicaid fees are associated with a higher probability of seeing any Medicaid patients and an increase in the share of a physician's patients covered by Medicaid. Baker and Royalty (2000) use a panel survey of physicians to analyze the relationship between Medicaid fee levels and the willingness of physicians to provide obstetric care to lowincome patients. Their results suggest that increases in Medicaid rates in the late 1980s shifted Medicaid patients from public sector physicians to ones in private practice. Similarly, Gruber, Adams and Newhouse (1997) find that an increase in Medicaid fees in Tennessee moved patients from outpatient clinics to physician offices. Other more recent studies also find that higher Medicaid fees are positively associated with the willingness of private physicians to treat Medicaid patients (Cunningham and Nichols 2005; Decker 2007).

The evidence on whether this supply response leads to an increase in overall utilization is mixed. Some studies using cross-sectional data find a significant relationship between Medicaid 
payment rates and the site of care, but find no significant relationship between payment rates and overall utilization (Long et al. 1986; Rosenbach 1989; Cohen and Cunningham 1995). However, other studies that analyze changes in fees suggest that access to physician services improves when Medicaid payments are increased (Gabel and Rice 1985; Shen and Zuckerman 2005; Decker 2009).

Much of the evidence on the relationship between Medicaid payment rates and dental care utilization comes from research on single states. For example, Hughes et al. (2005) and Nietert et al. (2005) find that higher Medicaid fees were associated with an increase in dental visits in Indiana and South Carolina, respectively. In contrast, Mayer et al. (2000) find no significant effect of an increase in Medicaid fees in North Carolina. A limitation of these studies is that because the fee increases were applied statewide, there are no contemporaneous comparison groups. In implementing CHIP some states chose to reimburse dentists more generously for CHIP patients than for Medicaid. Studies using data from North Carolina (Brickhouse et al. 2006) and Iowa (Damiano et al. 2008) find that children with CHIP coverage are more likely to have a dental visit than those with Medicaid. However, this difference may also reflect the fact that CHIP children are from higher income families who are more likely to have a history of private insurance and therefore are more likely to have had a regular source of dental care.

One single-state study with a more convincing research design examines a pilot program in Michigan where in selected counties Medicaid dental coverage was contracted out to a private insurer, which paid dentists at commercial rates (Eklund et al. 2003). The authors compared counties where payments increased to counties where the lower Medicaid rates still applied. In the program's first 12 months, the number of dentists treating Medicaid children increased 
significantly in the pilot counties, while participation remained essentially constant in the comparison counties. Changes in utilization followed a similar pattern.

The only existing national analysis of the impact of dental fee changes is a recent study by Decker (2011), who combines data from the 2000 and 2008 National Health Interview Surveys (NHIS) with information on how much each state Medicaid program paid for prophylaxis (cleaning) in those two years. She finds that for children covered by public health insurance, a \$10 increase in the Medicaid fee is associated with a nearly 4-percentage point increase in the probability of seeing a dentist in the past half-year.

\section{Data}

\section{Medicaid Payment Rates}

Our basic research design is similar to Decker's in that we combine state-specific payment rate data with nationally representative survey data to estimate the effect of fees on utilization controlling for state fixed effects. The data on dental reimbursement rates consist of Medicaid payment rates and private fees for 15 common dental procedures. The variables include the amount paid for a periodic oral exam (dental code D0120), a comprehensive oral exam (D0150), as well as thirteen other procedures. ${ }^{3}$

We assembled these data from a variety of sources. As a foundation, we used state level data on reimbursement schedules for 2002 and 2004 reported by the American Dental Association. We then hand-collected data for other years, contacting individual states when necessary. Where gaps remained, we used data from the Medicaid Analytic eXtract (MAX)

\footnotetext{
${ }^{3}$ The other procedure codes are: complete x-rays (D0210), bitewing x-rays (D0272), panoramic x-rays (D0330), child prophylaxis (D1120), application of topical fluoride (D1203), application of dental sealants (D1351), anterior tooth resin (D2331), permanent tooth amalgam (D2150), porcelain crown (D2751), prefabricated steel crown (D2930), therapeutic pulpotomy (D3220), root canal (D3310), and extraction (D7110).
} 
System. ${ }^{4}$ The MAX data were also useful for verifying that the amounts on the state fee schedules correspond with actual payments made.

Prior to 2001, the completeness of the data varies considerably across states, depending on the nature of the records of previous years' payment rates kept by the states. ${ }^{5}$ In order to ensure that our results are not biased by the fact that not all states are represented prior to 2001, our main analyses use data for the period from 2001 to $2010 .^{6}$ However, as a robustness check we also conduct analyses on a data extract spanning the period 1996 to 2010 . The results from this larger sample are not substantially different from the results for the years 2001 to 2010 .

To the extent that the willingness of dentists to treat publicly insured patients depends on payment rates, it should be the level of Medicaid rates relative to private market rates that matters. We obtained mean private market rates for the same billing codes from reports published by the American Dental Association based on surveys of its members. The ADA data are aggregated at the level of 9 regions and are reported every other year. For each state, we assign the mean fees for the appropriate region, taking a straight average of adjacent years to interpolate the missing years. Although the private fee levels differed across regions, all regions saw steady increases in private dental fees over this period, increases that typically exceeded inflation and sometimes by a substantial margin.

Figures 1 and 2 illustrate how Medicaid payment rates vary across states and over time. Figure 1 presents the real (\$2006) Medicaid payment for a comprehensive oral exam (payment code D0150); Figure 2 shows the same payment expressed as a percentage of the average private

\footnotetext{
4 We thank Todd Gilmer for providing the MAX data. More information on the data can be found in Gilmer and Kronick (2011).

${ }^{5}$ We were able to collect data beginning in 1997 or prior for only 24 states and the District of Columbia. For another 17 states our fee data begin in 1998 or 1999, and for four states we have no data prior to 2001.

${ }^{6}$ An additional reason for focusing on the more recent period is that in the late 1990s states were expanding public insurance eligibility and coverage by implementing CHIP. Since by 2001 all CHIP programs were in place, our analysis should not be confounded by changes in the composition of children eligible for public insurance.
} 
fee. The figures indicate that over this period many states experienced erosion in relative fees, although there were clearly exceptions when states increased their reimbursement rates substantially. ${ }^{7}$ In the later years, some states reduced nominal payment rates slightly in response to budget shortfalls. Because our regression analysis controls for state fixed effects, these jumps and declines provide the identification in our models of the impact of fees on utilization.

Table 1 summarizes the Medicaid payment rates in 2001 and 2010 for a selected set of billing codes. ${ }^{8}$ We also report the mean for an "expected fee index" that is formed by taking a weighted average of the 15 separate billing codes, where the weights are based on utilization patterns observed in Michigan's Medicaid program. The advantage of this variable is that it should capture shifts in the entire fee schedule, which is more likely to affect the decision of dentists than changes for a single procedure code. In the top panel, Medicaid payment rates are measured in constant (2006) dollars. In the lower panel, Medicaid rates are measured relative to private fees. Because over this period states were more likely to increase rather than decrease nominal rates, the mean payment for each procedure increased. However, because private fees were increasing by even more, the mean ratio of Medicaid to private fees declined for most procedures between 2001 and 2010. For example, the relative Medicaid payment rate for a periodic oral exam decreased from 62 percent to 54 percent and the relative rate for a comprehensive exam fell from roughly 50 percent to 46 percent.

If when states raise payment rates they apply a uniform increase to all billing codes, then data on any one code should capture the relevant variation. On the other hand, if states increase reimbursement for some procedures but not others, estimates of the effect of payment rates on

\footnotetext{
${ }^{7}$ Delaware is notable in paying dentists a percentage of private market fees, the only state to have such a fee assignment mechanism.

${ }^{8}$ The means in Table 1 are calculated by assigning to each observation in our SIPP sample the payment rate prevailing in that state and year and then taking the mean over the full sample using the SIPP sampling weight for the first month in the year. Thus, the figures in Table 1 represent population-weighted state means.
} 
utilization may be sensitive to the billing codes analyzed. Therefore, it is important to understand how changes in payment rates for a given state are correlated among the various procedure codes. To shed some light on this issue, we regressed each payment rate on a full set of state and year dummies and then calculated the correlations among the residuals from these regressions. Since in our main analysis we condition on state and year fixed effects, these residuals represent the variation that provides our identification. ${ }^{9}$

Table 2 presents selected results from this exercise. The table has 15 rows, one for each billing code for which we have fee data. For the sake of clarity, the columns are limited to a set of common procedures: standard and comprehensive oral exams, complete x-rays, child prophylaxis, topical fluoride, and dental sealants. For the most part, the correlations are high, suggesting that when states increase Medicaid payment rates they tend to increase payments for all procedures rather than a select few. The correlation between the two oral exam codes is 0.76 and each is highly correlated with most of the other codes. The payment code for child prophylaxis, which is what Decker (2011) uses in her analysis, is highly correlated with the two oral exam codes ( 0.81 for $\mathrm{D} 0120$ and 0.70 for D0150) and also with the other codes.

Correlations are especially high among similar procedures, such as the three types of x-rays. The payment code that is least correlated with others is the code for topical fluoride, with correlations ranging from 0.26 to 0.45 . The implication of the figures in Table 2 is that our results should not be sensitive to which variable we use as a proxy for Medicaid's payment policy (which is exactly what we find). Therefore, in presenting our results we will focus on the weighted average fee index as well as a limited number of common procedures.

\footnotetext{
${ }^{9}$ We also estimated regressions including only the state dummies. The results are nearly identical to the results from the model with state and year fixed effects.
} 


\section{The Survey of Income and Program Participation}

Our data on health insurance coverage and dental care utilization come from the SIPP, a nationally representative series of longitudinal data sets collected by the Census Bureau. Since we have complete Medicaid payment data starting in 2001, our main analysis uses data from SIPP panels beginning in 2001,2004 , and 2008. This produces a sample spanning the years 2001 to 2010, though because of the way the panels line up, we have no data for the years 2006 and 2007 (and only 246 observations from 2008). In the 2001 panel, five small states-Maine, North Dakota, South Dakota, Vermont and Wyoming — were not uniquely identified in the SIPP. We include observations from these states from the 2004 and 2008 panels in the models that we report, though dropping them has no material effect on the results.

SIPP respondents are surveyed every four months (each four month period is called a "wave") about their income, family composition, and participation in public programs since the last interview. In addition to these "core" questions, which are asked every wave, each wave of the survey includes selected "topical modules," with detailed questions on specific subjects. Two topical module questions on dental care utilization appear roughly annually, depending on the panel. For all children between the ages of 3 and 15, there is a question on the number of dental visits in the past 12 months. As shown in Table 3, roughly two-thirds of children between the ages of 3 and 15 had at least one dental visit in the past year. This is slightly lower than the utilization rates of over 70 percent in the NHIS, which asks a similar question (Decker 2011; Wall et al. 2012). Respondents who answer that their child has had a dental visit in the past year are then asked whether the child has ever had dental sealants applied to his or her teeth. All state Medicaid programs include sealants as a covered benefit and research shows that sealants are cost-effective for this population (Weintraub et al. 2001). Among children with a visit in the past 
year, 40 percent report ever having sealants applied. The unconditional mean for the sealant variable (i.e., coding children who did not have a visit in the prior year as zeroes) is 25 percent.

The core survey provides information on the type of health insurance held each month since the last interview. Using these data, it is possible to measure the number of months a child had insurance over the 12-month reference period for the topical module's utilization questions. A little more than one-third of the observations had public insurance at some time in the prior year. ${ }^{10}$ Over half of these children report 12 months of public coverage and more than threequarters are covered for at least 8 months. Therefore, in our analysis we use a binary measure of public insurance coverage that equals one for children who are observed with public coverage at any point in the prior 12 months and zero for children who never had public insurance during that interval. ${ }^{11}$ Our measure of private insurance includes employer-sponsored as well as individually purchased insurance. It is important to note that the SIPP survey does not ask explicitly about insurance coverage for dental care. Since not all private employers that provide health benefits offer dental coverage, we can expect that a certain number of children who are coded as having private insurance actually do not have coverage for dental care. ${ }^{12}$

\footnotetext{
${ }^{10}$ It is not possible in the SIPP to distinguish children who are enrolled in Medicaid and those who are in separate stand-alone CHIP programs. However, according to administrative data more than 80 percent of children with public insurance are enrolled through Medicaid rather than CHIP.

${ }^{11}$ Alternative measures, such as indicator variables for having public coverage for at least 6 months or at least 8 months yield similar results. We also experimented with dropping children who have fewer than 12 months of insurance data available and again the results were not different.

${ }^{12}$ According to 2007 data from the Bureau of Labor Statistics' National Compensation Survey, 71 percent of private industry workers had access to employer-sponsored health insurance and 46 percent were offered a dental plan.
} 


\section{The Effect of Medicaid Payment Rates on Dental Utilization}

\section{Regression Specification}

To estimate the effect of Medicaid payment rates on access to care, our baseline regression model is

$$
U_{T I L I Z} Z_{i s t}=X_{i s t}^{\prime} \beta+\gamma F E E_{s t}+\alpha P U B L I C_{i s t}+\delta P U B L I C_{i s t} \times F E E_{s t}+\theta_{s}+\tau_{t}+u_{i s t}
$$

where $U T I L I Z_{\text {ist }}$ is dental care utilization by child $i$ in state $s$ and year $t$. The utilization outcomes we analyze are a binary indicator for whether or not the child had at least one visit during the year, the total number of visits in the year and an indicator for whether the child reports having dental sealants applied. The vector $X_{i s t}$ consists of a standard set of child and family characteristics. $^{13}$ To control for time invariant differences across states and secular time trends, all models include state $\left(\theta_{s}\right)$ and year $\left(\tau_{t}\right)$ fixed effects. The state fixed effects are important for eliminating bias that might result from a correlation between Medicaid payment rates and other time-invariant state-level factors that influence access to care. By conditioning on these fixed effects, our estimates are identified by the within-state variation in Medicaid payment rates illustrated in Figures 1 and 2. One potential concern with this strategy is that some states may have raised payments because access problems were increasing over time. Such an example of policy endogeneity would cause the estimated effect of payment rates to be biased downward.

\footnotetext{
${ }^{13}$ The controls are: age (indicator variables for individual years), gender, race/ethnicity (white, black, Hispanic, other), child health status ( 5 categories), family income as a percentage of the FPL and its square, parent's education (4 categories), the number of children in the family, the number of months during the year that two parents were present in the household and an indicator variable for children who were uninsured for the entire year.
} 
To account for this possibility, we also estimate models that include state-specific linear time trends. As we discuss below, the results are robust to this inclusion.

The key independent variables are the Medicaid payment rate in state $s$ in year $t\left(F E E_{s t}\right)$ and an indicator for children who are covered by public insurance $\left(P U B L I C_{i s t}\right)$. We take two approaches with respect to the payment rate variable. In the first, payment rates are measured in constant (2006) dollars. An advantage of this specification is that the magnitude of the effect is easily interpreted: it represents the change in the probability of a visit or the mean number of visits corresponding to a $\$ 1$ increase in the per unit reimbursement rate. The disadvantage is that the absolute fee variables do not capture how Medicaid payment levels compare to the private market. Therefore, we also estimate models using the ratio of the Medicaid payment rate to the corresponding private market fee.

The coefficient on FEE, $\gamma$, represents the "effect" of Medicaid payment rates on dental care utilization on children who are not enrolled in Medicaid or CHIP. In theory, if dentists face a downward sloping demand in the private market and choose a mix of public and private patients so as to equate the marginal revenue from each source, higher Medicaid payments will cause dentists to increase prices, which would reduce the number of private patients treated. Such behavior would imply a negative coefficient on FEE. However, for several reasons we view such an effect to be unlikely. First, changes in Medicaid fees should have no direct effect on dentists that do not participate in the program. As we document below in our analysis of the ADA survey of dentists, even when fees increase, the majority of dentists do not treat any publicly insured patients. For those dentists who see a mix of public and private patients, the ability to increase private fees and the transmission of fee increases to patients will be mediated by dental insurance. Even if dentists are able to negotiate higher fees from private insurers, only 
a fraction of the fee increase will be passed along to patients in the form of higher co-payments. Therefore, our expectation is that $\gamma$ will be zero.

Note that because insurance coverage is endogenous, the coefficient on PUBLIC cannot be interpreted as a causal effect. Since $X$ includes an indicator variable for children who were uninsured for the entire year, $\alpha$ measures the difference in utilization between publicly and privately insured children (the omitted insurance category). Given the well-documented disparity in dental care utilization between children with private and public insurance, we expect $\alpha$ to be negative.

The parameter of primary interest is $\delta$, the coefficient on the interaction between $P U B L I C$ and FEE. The hypothesis that higher Medicaid payment rates lead to greater access to care for Medicaid enrollees implies that $\delta$ is positive. However, as noted, it is possible that higher Medicaid fees could increase the willingness of dentists to treat Medicaid patients and still have a negligible effect on total utilization. This would occur if the main effect of raising fees is to shift the source of care to private dental practices from free or subsidized clinics.

\section{Results}

In Table 4 we present key parameter estimates from linear probability models in which the dependent variable equals one if the child had at least one dental visit in the past year and zero otherwise. We report specifications using the Medicaid payment rate for two specific billing codes — comprehensive office visit (D0150) and child prophylaxis (D1120) — and the weighted average index of 15 codes. Models using other codes yield very similar results, which are available upon request. The rationale for focusing on the payment for comprehensive visits 
is that this is one of the two most common procedures billed by dentists. ${ }^{14}$ We report results for the prophylaxis code because that is the fee that Decker uses in her analysis.

Before turning to the results of primary interest, we briefly summarize the coefficients on the control variables (see Appendix Table). In all models, there are significant differences in utilization related to race and ethnicity, with white children having a higher probability of a visit than black or Hispanic children. Younger children are less likely to have a visit than older children, while children with more educated parents and children in higher income families are more likely to have a visit. The coefficients on the income variable and its square imply a difference of 3.5 percentage points between a child at 400 percent of poverty and one in a family whose income is equal to the poverty line, holding other factors constant.

As expected, the coefficient on PUBLIC is negative, indicating that children covered by Medicaid or CHIP are less likely to have a dental visit than children with private health insurance. However, there is an even larger gap in utilization between children with public insurance and those who were uninsured for all of the prior year. In all models, the coefficient on that variable is -0.3 . Although we attach no causal interpretation to these results, this pattern suggests that even if it does not provide the same level of access as private insurance, Medicaid does substantially improve access to dental care relative to being uninsured.

In all models, the "main effect" of the Medicaid payment rate variable is not significantly different from zero. In fact, in most cases the t-statistic is less than 1 . This result implies that increases in Medicaid fees do not affect the probability that a privately insured child has at least one dental visit, which is consistent with our expectations. Given that a significant coefficient on the fee variable would likely reflect a spurious correlation, we take this null result to indicate that

\footnotetext{
${ }^{14}$ The other most frequently submitted code is for a standard office visit (D0120). As shown in Table 2, changes in payments for these two codes are highly correlated. Results using this variable are very similar to the ones for the comprehensive office visit.
} 
the variation in fees that identifies our model is uncorrelated with important unmeasured factors affecting dental care use among children.

The results do indicate a positive relationship between Medicaid payment rates and access to care among publicly insured children. The magnitude of this effect is small relative to the regression-adjusted differences in utilization across insurance categories. When we use the Medicaid rate for a comprehensive visit as our proxy for a state's Medicaid payment policy the coefficients imply that a $\$ 10$ increase in the payment per visit increases the probability that a child has at least one visit by 1.3 percentage points. ${ }^{15}$ We obtain similar estimated effects when we use the payment rate for a standard office visit (results not shown) and child prophylaxis (column 2). This is slightly smaller than the effect that Decker finds in her analysis of the NHIS.

We obtain the largest estimated effect when we use the expected fee index. Those results imply that a $\$ 10$ increase in average Medicaid fees - a change slightly larger than the difference between the $75^{\text {th }}$ and $25^{\text {th }}$ percentiles for this variable-would lead to a roughly 3 percentage point increase in the probability that a publicly insured child has at least one dental visit in a year. This implied effect is slightly smaller than the regression adjusted difference between white children and either black (4.5 percentage points) or Hispanic children (3.5 percentage points).

Another way to put the results in context is to consider them in the context of specific policy proposals. For years, the American Dental Association (ADA) has argued that an effective strategy for improving access to dental care for publicly insured patients is "to increase Medicaid rates for all dental procedures to more closely mirror the marketplace," recommending that Medicaid rates be set at the $75^{\text {th }}$ percentile of private fees in a state (American Dental

\footnotetext{
${ }^{15}$ To put a $\$ 10$ increase in perspective, over the full sample there is a $\$ 13$ difference between the $75^{\text {th }}$ and $25^{\text {th }}$ percentile of this fee variable (\$33.11 vs. \$20.02).
} 
Association, 2004; p. 4). Since we do not observe the full distribution of private fees, we cannot simulate this exact proposal. However, we can use these results to get a sense of how utilization would increase if states increased their payments to equal the private market mean. Over the full 2001-2010 period, the mean of the weighted average relative fee index is 51 percent. Thus, on average to raise Medicaid fees to 100 percent of the private market rate would require an increase of 49 percentage points. The point estimate reported in column 4 implies that such an increase in Medicaid rates would boost the probability that a publicly insured child had at least one dental visit during the year by approximately 7 percentage points. To put this in perspective, such an effect is roughly two-thirds the magnitude of the regression-adjusted difference in the probability of a visit between a child with private health insurance and a child with public insurance indicated by the same specification (0.1052). This magnitude is reasonable given that dentists point to low fees as the most important, though not the only, factor explaining their reluctance to participate in Medicaid.

In Table 5 we report results for models in which the dependent variable is the total number of dental visits in a year, rather than the probability of having at least one visit. The pattern of results is similar to that in Table 4, though when we use the payment rate for child prophylaxis as our fee variable, the estimated coefficient is no longer statistically significant. The results using the other fee variables, however, are significant. The results in column 1 imply that a $\$ 10$ increase in the payment for a comprehensive office visit would increase the number of visits by 0.04 visits per year, or roughly 3 percent of the sample mean of 1.59 . The results using the fee index imply a slightly larger increase.

As noted, dental sealants have been found to be a cost-effective preventive treatment for children. In Table 6, we estimate regressions in which the dependent variable equals one if the 
child has had dental sealants applied to his or her teeth and zero otherwise. ${ }^{16}$ The layout is similar to Tables 4 and 5, though instead of the payment rate for prophylaxis we use the billing code for sealants (D1351). The overall pattern of results is consistent with the hypothesis that higher Medicaid payment rates induce greater utilization among publicly insured children, although the results are somewhat weaker than the results for visits. The coefficient on the interaction term is positive in all models, though when we use the code for sealants as our payment rate proxy, it is not statistically significant.

\section{Additional Regressions and Robustness Checks}

Our main specification restricts the effect of all variables besides $F E E$ to be the same for all children, regardless of insurance status. If utilization would have been trending differently for different income groups for reasons unrelated to the changes in Medicaid payments, this restriction may not be justified. Therefore, we also estimated all models on a sample that includes only children with public insurance. The estimated coefficients on the various payment rate variables were very similar to the coefficients on the interaction terms in Tables 4, 5 and 6 , indicating a positive and statistically significant relationship between Medicaid payment rates and dental care utilization for publicly insured children. ${ }^{17}$

As noted, for some states we have payment data going back as far as 1996 . We also have data from the 1996 SIPP panel, spanning the years 1996 to 2000 . When we add these additional observations to the sample and re-run the regressions we obtain results that are very similar in terms of sign, magnitude and statistical significance to those reported in the tables.

\footnotetext{
${ }^{16}$ Recall that there is an important limitation with this dependent variable, which is that the question on sealants is only asked if the child was reported to have had a dental visit in the past year. Therefore, children who did not have a visit in the most recent year but received sealants in a prior year will be miscoded.

${ }^{17}$ These results are available upon request.
} 
The fact that our results are so similar to what Decker obtains using the National Health Interview Survey suggests that our estimates are not an artifact of the SIPP data. As a further check, we estimate the relationship between Medicaid payment rates and dental care utilization using a third source: data from CMS Form 416, which states use to report to the Federal government the number of Medicaid children receiving preventive services. We combined 11 years (1999 to 2009) of state level data from Form 416 with our fee data and estimated regressions with two dependent variables: the percent of enrolled children receiving any dental treatment during the year and the percent receiving preventive dental care. ${ }^{18}$ The estimates, which are reported in Table 7, are very similar to what we find in the SIPP. For example, when we use the payment rate for a comprehensive office visit, the coefficient is 0.0017 , which is only slightly larger than the corresponding estimate from the SIPP (0.0013). Using the weighted average fee index, the estimated coefficient in the CMS data is 0.0020 , compared to 0.0032 in the most comparable SIPP model.

Regardless of the data source, there are two potential endogeneity concerns. One is that by making Medicaid dental coverage more attractive, increases in dental payment rates may increase program enrollment. Higher enrollment is not a problem per se, but it could affect our results if the marginal children induced to enter the program have a different demand for dental care than those who would have enrolled anyway. We cannot test for this second condition, but we can test for an effect of dental fees on enrollment by regressing Medicaid coverage on the various fee variables, along with state and year fixed effects and the same child and family characteristics that we use as controls in the utilization regressions.

\footnotetext{
${ }^{18}$ In some years, data are not available for all states. Our largest sample size for these regressions is 529 observations out of a possible 561 (51 states times 11 years).
} 
When we do this, we find no statistically significant relationship between Medicaid dental fees and Medicaid enrollment. The coefficient on the fee variable is actually negative, but with an absolute t-statistic of 1 or smaller. ${ }^{19}$ This null result is not surprising given that dental care represents a very small share of total Medicaid spending and is therefore unlikely to affect enrollment decisions. ${ }^{20}$

The second potential endogeneity concern is that states may have increased Medicaid dental rates in response to serious access problems. Conditional on the state fixed effects that we include in all models, this type of policy endogeneity is only a problem if the decision to increase payment rates was driven by state-specific changes in dental utilization. If so, our estimate of the effect of fees on utilization may pick up the effect of these pre-existing trends.

To account for this possibility, we add state-specific linear time trends to all models. The results are quite robust to this addition. Adding these variables increases the $\mathrm{R}^{2}$ only slightly and has little or no effect on the coefficient on the interaction between the Medicaid dummy and the various fee variables. For example, when the dependent variable is the indicator for at least one visit and the payment rate variable is the expected fee index, the $\mathrm{R}^{2}$ increases from .120 to .122 and the key coefficient goes from 0.0032 to $0.0029(\mathrm{t}$-statistic $=3.72)$. The changes in the coefficients are even smaller in the regressions using the other fee variables. Similarly, for the other dependent variables adding the linear time trends has little effect on the coefficient of interest or its standard error.

\footnotetext{
${ }^{19}$ For example, when we use the payment rate for a comprehensive oral exam as our fee proxy, the coefficient is -0.0002 with an absolute t-statistic of 0.73 . The results for the other fee variables are similar.

${ }^{20}$ Nationally, in 2012, dental care accounted for 1.1 percent of total Medicaid expenditures (Medicaid and CHIP Payment and Access Commission 2013).
} 
As an additional test, we use a two-step procedure to examine the relationship between the payment rate changes of our main analysis and earlier trends in dental care utilization for publicly insured children. The second stage involves the following state-level regression:

$$
\Delta F E E_{s}^{01-10}=\mu+\varphi U T I L I Z_{s}^{96-00}+v_{s}
$$

The dependent variable is the average annual change in Medicaid fees over the period 20012010. We construct this variable in the first step by regressing the Medicaid payment rate index on a linear time trend interacted with a full set of state dummies using the same augmented SIPP data that is the basis of our main analysis. The coefficients from the state-time interactions are then used as the dependent variables in (2). The trend in prior utilization is calculated in a similar fashion using data from the 1996 SIPP panel on dental utilization over the period 19962000.

The results from estimating (2) indicate no statistically significant relationship between payment rate increases during the period of our analysis and prior trends in utilization. The estimate of $\varphi$ is negative, but with an absolute t-statistic of 0.8 . This provides further evidence that policy endogeneity is not an important source of bias for our estimates of the effect of Medicaid payment rates on utilization.

\section{The Effect of Medicaid Payments on Program Participation by Dentists}

The utilization results are consistent with the hypothesis that higher reimbursement increases the willingness of dentists to accept Medicaid. To test this hypothesis directly, we turn to data from the ADA's annual Survey of Dental Practice (SDP), a mail survey that asks about various aspects of a dental practice, including the percentage of patients that are covered by 
private insurance, public insurance and no insurance. ${ }^{21}$ Our analysis is based on SDP data covering the years 1999 to 2009.

Table 8 reports summary statistics for these data. Fifty-six percent of the dentists in our sample are general practitioners. The vast majority practice in a single location and slightly more than half are the only dentists in their practice. Over the full period just over one-third of dentists (38.1 percent) report treating some publicly insured patients. The unconditional mean of the percentage of a dentist's patients with public insurance is 6.3 percent. The conditional mean (among those dentists seeing any public patients) is 16.6 percent.

To test for an effect of Medicaid payment rates on the supply of services to publicly insured patients, we estimate regressions of the form:

$$
P_{d s t}=Z_{d s t}{ }^{\prime} \pi+\rho F E E_{s t}+\sigma_{s}+\eta_{t}+e_{d s t}
$$

where the dependent variable is either the percentage of patients with public insurance or a binary variable that equals one if the dentists reports seeing any public patients; $Z$ is a vector of controls; ${ }^{22}$ FEE is one of the payment rate variables used in the SIPP analysis and $\sigma_{s}$ and $\eta_{t}$ are state and year fixed effects.

The results from these regressions are reported in Table 9. For both dependent variables and for all payment rate variables we find a positive effect of payment rates. Every estimate but one is statistically significant at conventional levels. For the participation regressions, the

\footnotetext{
${ }^{21}$ The question is worded as follows: "Approximately what percentage of all the patients who visited the entire primary practice in [year] were: covered by a private insurance program that pays or partially pays for their dental care? Covered by a public assistance program that pays or partially pays for their dental care? Not covered by an insurance program?"

${ }^{22}$ The controls are: whether the dentist is a general practitioner, whether the practice has multiple locations, the number of dentists in the practice (4 categories including the omitted category) and the percent of the practice's patients that are less than 18 years old.
} 
estimate of $\rho$ ranges from 0.0015 for a comprehensive oral evaluation to 0.0031 when we use the weighted average fee index as our payment rate proxy. Evaluated at the sample means for our data, these point estimates translate to elasticities ranging from 0.097 to 0.208 . The upper estimate is similar to the supply elasticity that Sloan et al. (1978) and Decker (2007) estimate in their studies of physician participation in Medicaid.

When the dependent variable is public patients as a percentage of all the practice's patients, the coefficient on the Medicaid payment variable ranges from 0.032 when we use the payment rate for a comprehensive oral exam to 0.059 in the model with the payment rate for prophylaxis. The corresponding elasticities range from 0.124 to 0.229 . The larger figure is slightly smaller than the supply elasticity of 0.30 which is implied by Baker and Royalty's (2000) analysis of physicians and slightly lower than the results of Decker (2007), whose estimates imply an elasticity of 0.40 .

\section{Policy Implications}

Overall, the regression results are consistent with the hypothesis that increasing Medicaid payments to dentists would increase the utilization of dental care among children enrolled in the program. However, whether or not this is a desirable policy will depend on how the benefit of these additional visits compares to the cost of the policy. There is no information in the SIPP or the ADA-SDP data that would allow us to say anything about the health benefits of increased dental care utilization, but with some assumptions it is possible to use the coefficient estimates from Table 5 to calculate rough estimates of the cost of the additional visits that would be induced by an increase in Medicaid rates. That incremental cost can be calculated as the ratio of the change in spending per child to the change in the number of visits: 


$$
\frac{\Delta C}{\Delta V}=\frac{\tilde{P} \odot \hat{V}(\tilde{P})-\bar{P} \odot \hat{V}\left(\bar{P}^{\text {Med }}\right)}{\hat{V}(\tilde{P})-\hat{V}\left(\bar{P}^{\text {Med }}\right)}
$$

In this equation, $\hat{V}(P)$ represents the predicted number of visits corresponding to a given payment rate, $P . \quad \bar{P}^{\text {Med }}$ is the average Medicaid payment rate for a dental visit under current policy and $\tilde{P}$ is the higher rate under an alternative policy.

Over the full time period, the average Medicaid reimbursement for a dental procedure (based on our weighted average index) was $\$ 26.54$, or 52 percent of the average private sector fee (\$51.04). Suppose all states were to follow Delaware and set their dental payment rates at 85 percent of the private market average. This would mean raising the average Medicaid payment to $\$ 43.38$, an increase of $\$ 16.84$ per procedure. According to the coefficient estimate in column 5 of Table 5, such an increase in Medicaid rates would increase the average number of visits per child per year by 0.12 visits per year $(0.0072 \times \$ 16.84)$, or by 9 percent relative to the mean of 1.27 visits per year for Medicaid children. This is the denominator for our incremental cost calculation.

The numerator is the difference in the cost per child—calculated as the average number of visits times the cost per visit—-between the two scenarios. The cost per visit will depend on how many and which procedures are performed. In the SIPP data, we have no information on what services are provided during dental visits. Assuming an average of one procedure per visit should generate a lower bound estimate. Using the weighted average fee index, the cost per child under the counterfactual scenario is $\$ 60.46$ ( $\$ 43.38$ per visit times 1.39 visits) and the cost per child at current Medicaid rates is $\$ 33.75$ ( $\$ 26.54 \times 1.27)$. Thus, $\Delta \mathrm{C}=\$ 26.72$. Dividing this figure by $\Delta \mathrm{V}(0.12)$ yields an incremental cost per visit of $\$ 218.84$. The regression using the fee for a comprehensive oral exam yields a larger estimate (\$290) because the key coefficient is 
slightly smaller $(0.005)$ and a larger fee increase $(\$ 20.34)$ is required to get to 85 percent of the private market mean.

This clearly is a rough calculation and there are reasons why it might either overstate or understate the true incremental cost per visit. On one hand, to the extent that our payment rate variables are subject to classical measurement error, we may be understating the effect of a fee increase on utilization. If this is the case, the denominator of this equation will be too small, causing our estimate of the incremental cost to be too high. On the other hand, the assumption that only one procedure is performed per visit almost certainly causes the cost per child to be understated.

It is unlikely, however, that eliminating these potential biases would change the basic conclusion, which is that the incremental cost of the additional visits induced by increasing Medicaid provider payments from their current level is very high relative to the average level of private fees. This result comes from the fact that the effect of payment rates on visits is relatively small. Because raising Medicaid rates to 85 percent of mean private fees increases utilization by only 9 percent, roughly 90 percent of the cost of the fee increase comes from paying more for visits that would have occurred under the lower Medicaid fee schedule.

\section{Conclusion}

Over the past two decades, there was a substantial increase in the number of American children covered by public health insurance. Starting in 2014, the Affordable Care Act will continue the expansion of public insurance coverage by extending Medicaid eligibility to lowincome adults. The potential for these insurance expansions to improve access to health care services for low-income patients depends on whether or not there is an adequate supply of 
providers willing to treat publicly insured patients. Medicaid payment policy is a critical lever for influencing supply.

The problem of low provider participation has been especially acute in the area of dental care. In many states, Medicaid payment for dental services is well below average rates in the private market and this gap in fees is commonly cited as a primary reason that many dentists either limit the number of Medicaid patients they see or refuse to accept Medicaid patients at all. This low rate of provider participation is in turn cited as an important explanation for large income-related disparities in dental care utilization and oral health among children.

In recent years, a number of states have significantly increased Medicaid reimbursement rates for dental care. We exploit these changes to estimate the effect of Medicaid payment policy on children's dental care utilization. The results suggest that higher payment rates do result in higher rates of utilization. In our data, a $\$ 10$ increase in the payment rate for an office visit raises the probability of an annual dental visit by 1.3 percentage points. We find a similar positive relationship between Medicaid dental fees and the number of dental visits in a year and slightly weaker though still positive effects on the probability that a child received dental sealants. The finding that higher Medicaid payments lead to greater utilization for children covered by Medicaid is robust to the use of different fee variables and to whether we measure Medicaid fees in constant dollars or relative to the mean fees charged to private payers. Our findings regarding the effect of these payment rate variables on utilization by other children are also quite robust. In all specifications, we find no significant relationship between Medicaid payment rates and utilization by children who were not publicly insured. We take this null result as support for the validity of our empirical specification. 
The most plausible mechanism that could explain a positive relationship between Medicaid payment rates and the utilization of dental care is that higher payments increase the supply of services to Medicaid patients by inducing more dentists to participate in the program. Our analysis of data from the American Dental Association's Survey of Dental Practice is consistent with this hypothesis. We find a positive and significant effect of Medicaid rates on the probability that a dentist treats any publicly insured patients and on the share of the practice's patients covered by public insurance. The implied elasticities are roughly similar to what prior studies have found for physicians.

Although these results suggest that increasing Medicaid payments to the level of private fees would increase access to care, the magnitude of the effect is modest. As a result, such a policy would be a costly way to increase utilization as increased payments for inframarginal visits would dwarf payments for the additional visits caused by the policy. Other strategies for increasing access to dental care for low-income patients may be more cost-effective. For example, legislation recently enacted in Minnesota provides greater professional autonomy for new dental practitioners, called dental therapists. These mid-level providers have more training than dental hygienists and less training than dentists and are qualified to provide much of the care currently provided by dentists. A substantial literature documents that the quality of care provided by dental therapists for the set of procedures they are allowed to perform is comparable to the quality of care provided by dentists (for a recent review, see Phillips and Shaefer 2013). To the extent that they are more willing than dentists to accept Medicaid reimbursement rates, increasing the supply of dental therapists may be a less costly way to improve access to care.

Several limitations of our work suggest directions for future research. Although important, payment policy is not the only policy tool available to state Medicaid programs. 
Dentists have pointed to other problems with accepting Medicaid patients besides low reimbursement rates, including administrative requirements of Medicaid and patient issues such as frequently missed appointments (US GAO 200b). Changes in administrative processes that reduce the "hassle" of contracting with Medicaid may also increase the willingness of dentists to participate in the program. To this end, some states have contracted with private firms to administer dental benefits. It would be valuable to understand the effect of this approach holding constant the effect of payment rate levels.

Additionally, while the SIPP data used in this analysis has important strengths, it was not designed as a health care survey, let alone a survey of dental care. As a result, the measures of utilization are quite limited. Although it is important to understand how Medicaid policy affects the probability that children have a periodic dental visit, it is also important to understand the content of those visits. Analyses using visit-level claims data would shed light on the mix of dental services received by Medicaid children. 


\section{References}

American Academy of Pediatric Dentistry, 2009. "Guideline on Periodicity of Examination, Preventive Dental Services, Anticipatory Guidance/Counseling, and Oral Treatment for Infants, Children, and Adolescents": http://www.aapd.org/media/Policies Guidelines/G Periodicity.pdf.

American Dental Association, 2004. State and Community Models for Improving Access to Dental Care for the Underserved - A White Paper. (October): http://www.ada.org/sections/advocacy/pdfs/topics_access_whitepaper.pdf.

Baker, L.C., Royalty, A.B., 2000. "Medicaid Policy, Physician Behavior, and Health Care for the Low-Income Population," Journal of Human Resources, 35(3): 480-502.

Brickhouse, T.H., Rozier, R.G., Slade, G.D., 2006. “The Effect of Two Publicly Funded Insurance Programs on Use of Dental Services for Young Children," Health Services Research, Dec; 41(6): 2033-53.

Centers for Medicare and Medicaid Services, 2004. Guide to Children's Dental Care in Medicaid: http://medicaid.gov/Medicaid-CHIP-Program-Information/ByTopics/Benefits/Downloads/Child-Dental-Guide.pdf

Cohen, J., Cunningham, P.J., 1995. "Medicaid Physician Fee Levels and Children's Access to Care," Health Affairs, 13:255-262.

Cunningham, P.J., Nichols, L., 2005. "The Effects of Medicaid Reimbursement on the Access to Care of Medicaid Enrollees: A Community Perspective," Medical Care Research and Review, 62(6): 676-696.

Damiano, P.C., Brown, E.R., Johnson, J.D., Scheetz, J.P., 1990. "Factors affecting dentist participation in a state Medicaid program," Journal of Dental Education, 54(11): 638643.

Damiano, P. C., Momany, E. T., Carter, K. D., Jones, M. P., Askelson, N. M., 2008. "Time to First Dental Visit after Initially Enrolling in Medicaid and S-SCHIP." Medical Care 46(12): 1234-9.

Decker, S.L., 2007. "Medicaid Physician Fees and the Quality of Medical Care of Medicaid Patients in the USA," Review of Economics of the Household, 5:95-112.

Decker, S.L., 2009. "Changes in Medicaid Physician Fees and Patterns of Ambulatory Care," Inquiry, 46: 291-304.

Decker, S. L., 2011. "Medicaid Payment Levels to Dentists and Access to Dental Care Among Children and Adolescents," Journal of the American Medical Association, 306(2): 187193 (July 13, 2011). 
DeNavas-Walt, C., Proctor, B. D., Smith, J. C., 2012. Income, Poverty, and Health Insurance Coverage in the United States: 2011. U.S. Census Bureau, Current Population Reports, P60-243, U.S. Government Printing Office, Washington, DC.

Eklund, S.A., Pittman, J.L., Clark, S.J., 2003. "Michigan Medicaid's Healthy Kids Dental Program," Journal of the American Dental Association, 134(11): 1509-1515.

Fisher-Owens, S.A., Barker, J.C., Adams, S., Chung, L.H., Gansky, S.A., Hyde, S., Weintraub, J.A., 2008. "Giving Policy Some Teeth: Routes to Reducing Disparities in Oral Health," Health Affairs 27(2): 404-412.

Gabel, J.R., Rice, T.H., 1985. "Reducing Public Expenditures for Physician Services: The Price of Paying Less," Journal of Health Politics, Policy and Law, 9(4): 595-609.

Gift, H.C., Reisine, S.T., Larach, D.C., 1992. "The Social Impact of Dental Problems and Visits," American Journal of Public Health, 82(12):1663-1668.

Gilmer, T.P., Kronick, R.G., 2011. "Differences in the Volume of Services and in Prices Drive Big Variations in Medicaid Spending Among US States and Regions," Health Affairs, 30(7): 1316-1324.

Glied, S., Neidell, M., 2010. "The Economic Value of Teeth.” Journal of Human Resources, 45(2): 468-496.

Grover, J.S., 2008. Statement to the Subcommittee on Domestic Policy of the Committee on Oversight and Government Reform, Hearing on "Necessary Reform to Pediatric Dental Care Under Medicaid," U.S. House of Representatives, 110 Congress, Second Session, U.S. Government Printing Office No. 110-190 (September 23): http://www.gpo.gov/fdsys/pkg/CHRG-110hhrg51701/html/CHRG-110hhrg51701.htm.

Gruber, J., Adams, K., Newhouse, J.P. 1997. "Physician Fee Policy and Medicaid Program Costs," Journal of Human Resources, 32(4): 611-634.

Hughes R. J., Damiano, P.C., Kanellis, M. J., Kuthy, R., Slayton, R. 2005. “Dentists' participation and children's use of services in the Indiana dental Medicaid program and SCHIP: Assessing the impact of increased fees and administrative changes," Journal of the American Dental Association 136(4): 517-523.

Kenney, G.M., McFeeters, J.R., Yee, J.Y. 2005. "Preventive Dental Care and Unmet Dental Needs Among Low-Income Children.” American Journal of Public Health 95:1360 1366.

Long, S.H., Settle, R.F., Stuart, B.C., 1986. "Reimbursement and Access to Physicians' Services Under Medicaid." Journal of Health Economics 5(3): 235- 251. 
Manski, R.J., Edelstein, B.L., Moeller, J.F., 2001. "The Impact of Insurance Coverage on Children's Dental Visits and Expenditures, 1996." Journal of the American Dental Association, 132:1137-1145.

Manski, R.J., Macek, M.D., Moeller, J.F., 2002. "Private Dental Coverage. Who Has It and How Does it Influence Dental Visits and Expenditures?" Journal of the American Dental Association, 133: 1551-1559.

Mayer, M.L., Stearns, S.C., Norton, E.C., Rozier, R.G., 2000. "The Effect of Medicaid Expansions and Reimbursement Increases on Dentists' Participation," Inquiry 37(1):3344.

Medicaid and CHIP Payment and Access Commission. 2013. Report to the Congress on Medicaid and CHIP (March 2013).

Mouradian, W.E., Wehr, E., Crall, J.J., 2000. "Disparities in Children's Oral Health and Access to Dental Care," JAMA 284(20): 2625-2631.

Newacheck, P.W., Hughes, D.C. , Hung, Y.Y., Wong, S., Stoddard, J.J., 2000. “The Unmet Health Needs of America's Children," Pediatrics, 105(4 pt. 2): 989-997.

Nietert, P.J., Bradford, W.D., Kaste, L.M., 2005. "The Impact of an Innovative Reform to the South Carolina Dental Medicaid System," Health Services Research, 40(4): 1078-1091.

Perkins, J., 2007. "Docket of Medicaid Cases to Improve Dental Access," National Health Law Program: http://www.healthlaw.org/images/stories/issues/dentaldocket.2007.pdf

Phillips, E.H., Shaefer, H.L., 2013. "Dental therapists: evidence on technical competence," Journal of Dental Research, 92(7 Suppl.):S11-S15.

Rosenbach, M.L., 1989. "The Impact of Medicaid on Physician Use by Low-Income Children," American Journal of Public Health, 79(9): 1220-1226.

Shen, Y.C., Zuckerman, S., 2005. "The Effect of Medicaid Payment Generosity on Access and Use Among Beneficiaries," Health Services Research, 40(3): 723-744.

Sloan, F., Mitchell, J., Cromwell, J., 1978. "Physician Participation in State Medicaid Programs," Journal of Human Resources 13 (supplement): 909-940.

Sohn, W., Ismail, A., Amaya, A., Lepowski, J., 2007. "Determinants of Dental Care Visits Among Low-Income African-American Children," Journal of the American Dental Association, 138: 309-317. 
U.S. Department of Health and Human Services (DHHS). 2000. "Oral Health in America: A Report of the Surgeon General." Rockville, MD: U.S. Department of Health and Human Services, National Institute of Dental and Craniofacial Research, National Institutes of Health: http://silk.nih.gov/public/hck1ocv.@,www.surgeon.fullrpt.pdf.

United States General Accounting Office (GAO). 2000a. "Oral Health: Dental Disease is a Chronic Problem Among Low-Income Populations." GAO/HEHS-00-72. Washington, D.C.: GAO, September.

United States General Accounting Office (GAO). 2000b. "Factors Contributing to Low Use of Dental Services by Low-Income Populations." GAO/HEHS-00-149. Washington, D.C.: GAO, September.

United States General Accounting Office (GAO). 2010. "Efforts Underway to Improve Children's Access to Dental Services But Sustained Attention Needed to Address Ongoing Concerns," GAO-11-96. Washington, D.C.: GAO, November.

Wall, T.P., Vujicic, M., Nasseh, K., 2012. "Recent Trends in the Utilization of Dental Care in the United States," Journal of Dental Education, 76(8): 1020-1027.

Weintraub, J.A., Stearns, S.C., Rozier, R.G., Huang, C.C., 2001. "Treatment Outcomes and Costs of Dental Sealants Among Children Enrolled in Medicaid," American Journal of Public Health 91(11):1877-1881. 
Figure 1. Medicaid Payment Rates for a Comprehensive Oral Exam (D0150) 2001 to 2010

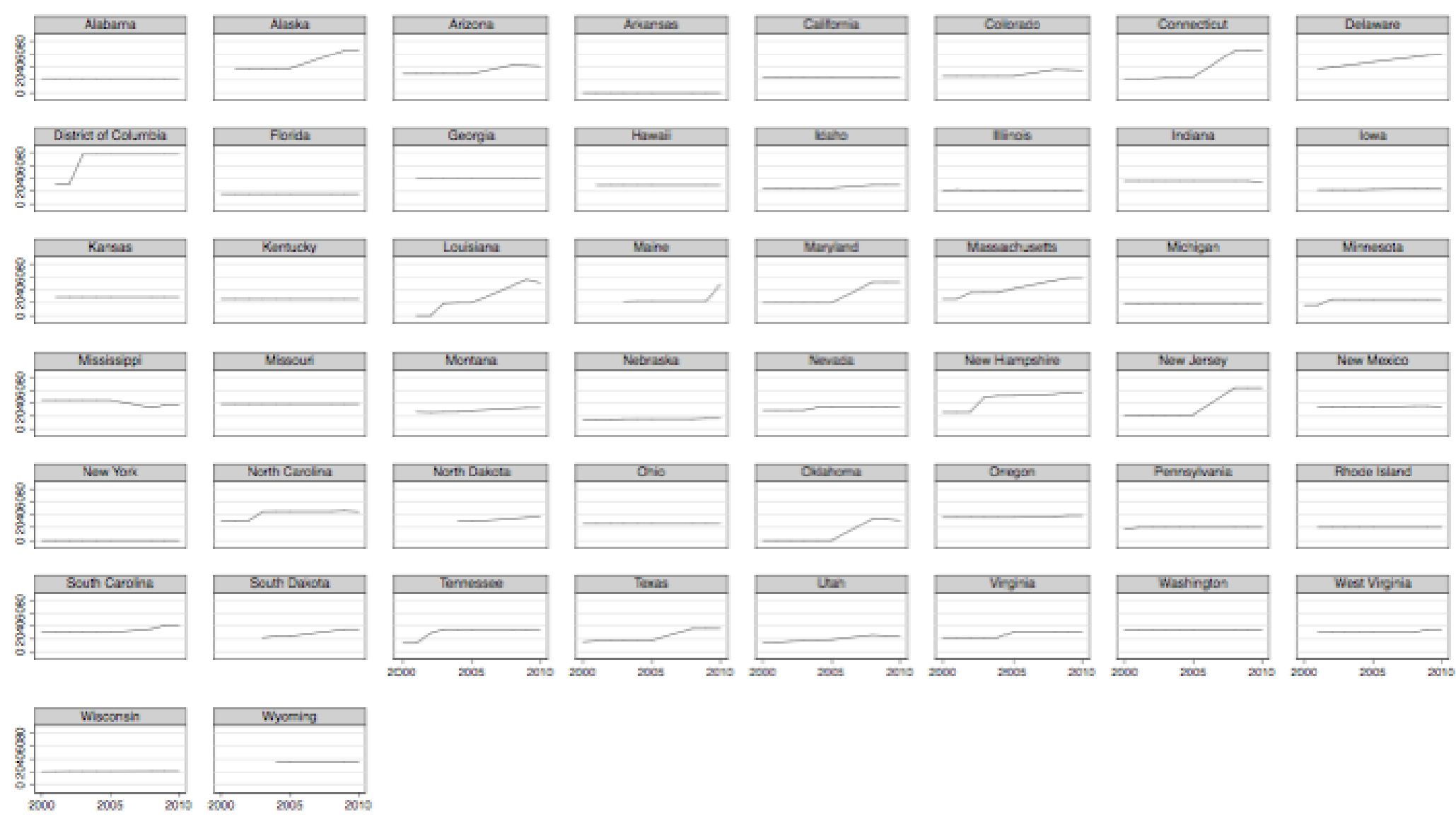


Figure 2. Medicaid/Private Fee Ratio for a Comprehensive Oral Exam (D0150) 2001 to 2010
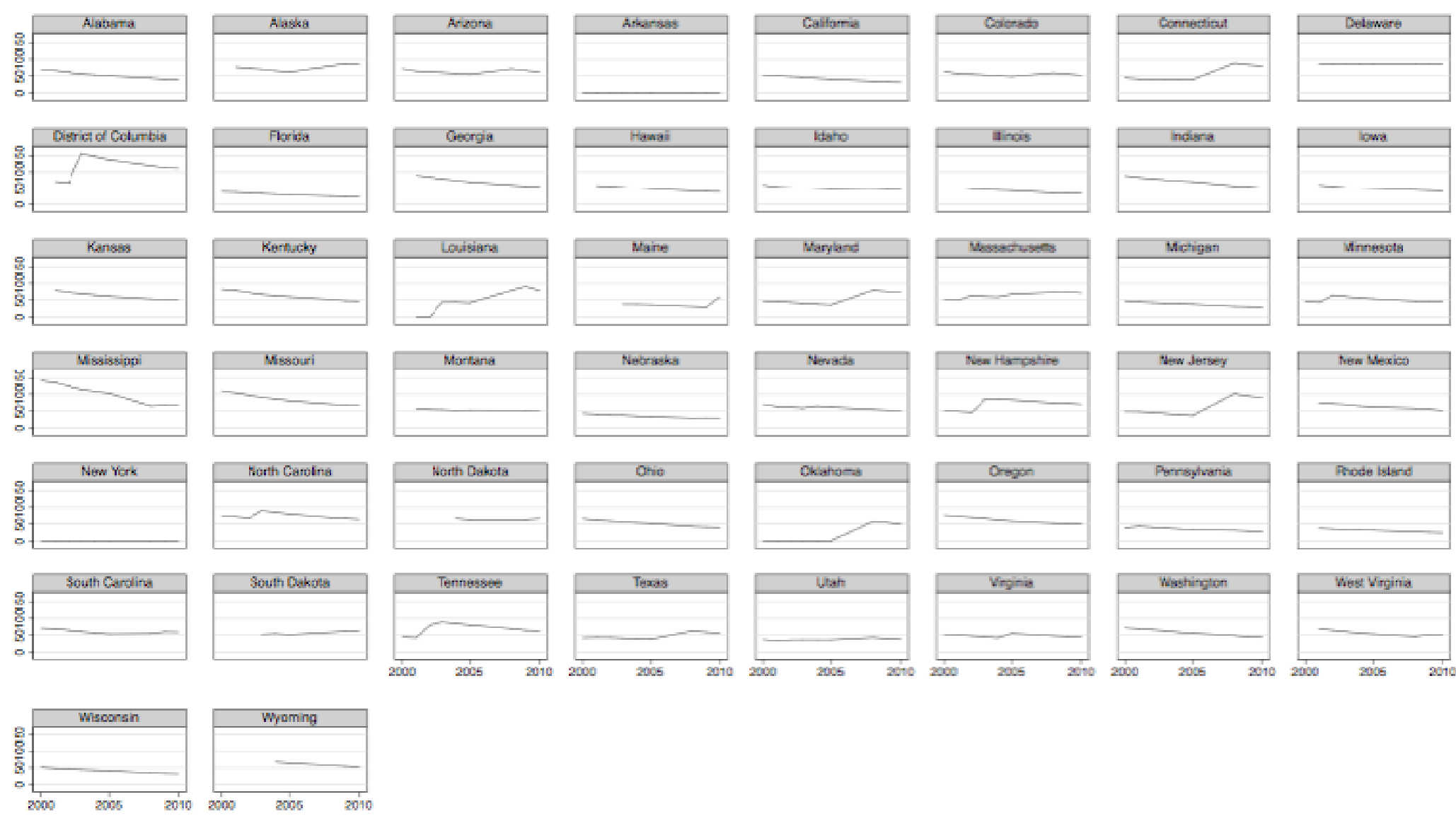
Table 1. Selected Medicaid Fees, 2001 and 2010

\begin{tabular}{|c|c|c|c|c|c|c|}
\hline & & 2001 & & & 2010 & \\
\hline & $\begin{array}{c}\text { Mean } \\
\text { (Std. } \\
\text { Dev.) }\end{array}$ & $\begin{array}{c}25^{\text {th }} \\
\text { Percentile }\end{array}$ & $\begin{array}{c}75^{\text {th }} \\
\text { Percentile }\end{array}$ & $\begin{array}{c}\text { Mean } \\
\text { (Std. } \\
\text { Dev.) }\end{array}$ & $\begin{array}{c}25^{\text {th }} \\
\text { Percentile }\end{array}$ & $\begin{array}{c}75^{\text {th }} \\
\text { Percentile }\end{array}$ \\
\hline I. Medicaid fee (\$2006) & & & & & & \\
\hline Periodic oral exam (D0120) & $\begin{array}{l}\$ 19.51 \\
\quad(6.07)\end{array}$ & $\$ 16.73$ & $\$ 23.86$ & $\begin{array}{r}\$ 20.67 \\
(6.68)\end{array}$ & $\$ 14.72$ & $\$ 26.69$ \\
\hline $\begin{array}{l}\text { Comprehensive oral exam } \\
\text { (D0150) }\end{array}$ & $\begin{array}{c}24.91 \\
(11.25)\end{array}$ & 20.46 & 29.83 & $\begin{array}{l}27.87 \\
(13.36)\end{array}$ & 19.51 & 34.21 \\
\hline Child prophylaxis (D1120) & $\begin{array}{l}27.71 \\
(9.19)\end{array}$ & 21.30 & 34.05 & $\begin{array}{l}29.85 \\
(8.78)\end{array}$ & 25.05 & 34.67 \\
\hline Topical fluoride (D1203) & $\begin{array}{l}11.84 \\
(7.28)\end{array}$ & 8.49 & 17.05 & $\begin{array}{l}15.81 \\
(4.16)\end{array}$ & 12.94 & 17.54 \\
\hline Dental sealant (D1351) & $\begin{array}{l}23.55 \\
(7.70)\end{array}$ & 18.39 & 27.85 & $\begin{array}{l}24.52 \\
(7.29)\end{array}$ & 20.05 & 26.64 \\
\hline Expected fee index & $\begin{array}{l}25.75 \\
(6.05)\end{array}$ & 22.43 & 28.38 & $\begin{array}{l}28.29 \\
(7.40)\end{array}$ & 23.30 & 32.69 \\
\hline II. Medicaid as a percent & private & & & & & \\
\hline Periodic oral exam (D0120) & $\begin{array}{l}61.63 \% \\
(19.84)\end{array}$ & $50.25 \%$ & $76.70 \%$ & $\begin{array}{l}53.24 \% \\
(18.42)\end{array}$ & $39.28 \%$ & $69.08 \%$ \\
\hline $\begin{array}{l}\text { Comprehensive oral exam } \\
\text { (D0150) }\end{array}$ & $\begin{array}{c}50.63 \\
(24.19)\end{array}$ & 43.16 & 61.88 & $\begin{array}{l}44.53 \\
(20.66)\end{array}$ & 31.96 & 56.73 \\
\hline Child prophylaxis (D1120) & $\begin{array}{c}57.70 \\
(18.99)\end{array}$ & 48.03 & 68.27 & $\begin{array}{c}55.37 \\
(17.28)\end{array}$ & 40.22 & 70.80 \\
\hline Topical fluoride (D1203) & $\begin{array}{l}47.66 \\
(29.58)\end{array}$ & 33.64 & 68.00 & $\begin{array}{c}56.80 \\
(14.39)\end{array}$ & 47.60 & 66.58 \\
\hline Dental sealant (D1351) & $\begin{array}{l}65.50 \\
(21.16)\end{array}$ & 51.33 & 75.57 & $\begin{array}{c}59.00 \\
(17.84)\end{array}$ & 40.21 & 68.80 \\
\hline Expected fee index & $\begin{array}{c}54.87 \\
(13.46) \\
\end{array}$ & 42.61 & 62.53 & $\begin{array}{c}50.94 \\
(13.77) \\
\end{array}$ & 37.83 & 62.27 \\
\hline
\end{tabular}

Notes: Population-weighted state means. See text for description of sources. 
Table 2. Selected Correlations of Medicaid Payment Rates Residuals by Billing Code

\begin{tabular}{lcccccc}
\hline \hline & D0120 & D0150 & D0210 & D1120 & D1203 & D1351 \\
\hline Periodic Oral Exam (D0120) & 1.00 & & & & & \\
Comprehensive Oral Exam (D0150) & 0.77 & 1.00 & & & & \\
Complete X-rays (D0210) & 0.83 & 0.78 & 1.00 & & & \\
Bitewing X-rays (D0272) & 0.85 & 0.73 & 0.94 & & & \\
Panoramic X-rays (D0330) & 0.83 & 0.79 & 0.96 & & & \\
Child prophylaxis (D1120) & 0.81 & 0.71 & 0.77 & 1.00 & & \\
Topical Flouride (D1203) & 0.42 & 0.38 & 0.46 & 0.44 & 1.00 & \\
Dental Sealant (D1351) & 0.89 & 0.73 & 0.72 & 0.81 & 0.47 & 1.00 \\
Amalgam (D2150) & 0.86 & 0.79 & 0.88 & 0.78 & 0.43 & 0.78 \\
Anterior Tooth Resin (D2331) & 0.86 & 0.84 & 0.89 & 0.81 & 0.46 & 0.81 \\
Porcelain Crown (D2751) & 0.50 & 0.38 & 0.60 & 0.44 & 0.22 & 0.42 \\
Pre-fabricated Steel Crown (D2930) & 0.84 & 0.79 & 0.86 & 0.77 & 0.43 & 0.78 \\
Therapeutic Pulpotomy (D3220) & 0.76 & 0.75 & 0.88 & 0.77 & 0.44 & 0.78 \\
Root Canal (D3310) & 0.74 & 0.70 & 0.88 & 0.74 & 0.40 & 0.72 \\
Extraction (D7110) & 0.74 & 0.77 & 0.76 & 0.71 & 0.33 & 0.73 \\
\hline \hline
\end{tabular}

Notes: The figures in each cell represent the correlation between residuals from regressions of the payment rate for each billing code on a full set of state and year fixed effects. 
Table 3. SIPP Data—Summary Statistics

\begin{tabular}{lrr}
\hline \hline & Mean & $\begin{array}{r}\text { Standard } \\
\text { deviation }\end{array}$ \\
\cline { 2 - 3 } Dental care outcomes: & & \\
At least one dental visit in past year & & 0.469 \\
Number of dental visits in past year & 1.591 & 2.453 \\
Ever sealants applied & 0.227 & 0.419 \\
Insurance coverage: & & \\
Any public coverage in past year & & 0.477 \\
Uninsured all of past year & 0.351 & 0.236 \\
Child characteristics: & 0.059 & \\
Health status excellent & & 0.494 \\
Health status very good & & 0.449 \\
Health status good & 0.576 & 0.334 \\
Health status fair & 0.279 & 0.131 \\
Health status poor & 0.128 & 0.052 \\
Male & 0.018 & 0.500 \\
Black & 0.003 & 0.349 \\
Hispanic & 0.509 & 0.378 \\
Other race & 0.142 & 0.262 \\
Family characteristics: & 0.173 & \\
Average income as percent of poverty level & 0.074 & 317.418 \\
Months with two parents in family & & 5.407 \\
Number of children in the family & 303.006 & 1.200 \\
\hline \hline
\end{tabular}

Source: Authors' calculations from 2001, 2004, 2008 SIPP. Sample limited to children aged 3 to $15(n=109,786)$. Question about sealant use was only asked of children who had at least one dental visit in the past year. 
Table 4. Regression Results: Probability of Having One or More Visit in the Past Year
(1)
(2)
(3)
(4)

\begin{tabular}{llllc} 
Billing code: & $\begin{array}{c}\text { D0150 } \\
\text { Comp. oral } \\
\text { exam } \\
\mathbf{( \$ 2 0 0 6 )}\end{array}$ & $\begin{array}{c}\text { D1120 } \\
\text { Child } \\
\text { prophylaxis } \\
\mathbf{( \$ 2 0 0 6 )}\end{array}$ & $\begin{array}{c}\text { Expected } \\
\text { fee index } \\
\mathbf{( \$ 2 0 0 6 )}\end{array}$ & $\begin{array}{c}\text { Expected } \\
\text { fee index } \\
\text { (pub./priv.) }\end{array}$ \\
\hline Public insurance & $-0.0623^{* *}$ & $-0.0670^{* *}$ & $-0.1112^{* *}$ & $-0.1052^{* *}$ \\
& $(0.0132)$ & $(0.0182)$ & $(0.0233)$ & $(0.0208)$ \\
Medicaid payment rate & 0.0001 & -0.0002 & -0.0008 & -0.0004 \\
Public insurance x Medicaid payment rate & $(0.0005)$ & $(0.0006)$ & $(0.0008)$ & $(0.0004)$ \\
& $0.0013^{* *}$ & $0.0014 * *$ & $0.0032^{* *}$ & $0.0015^{* *}$ \\
\hline \hline
\end{tabular}

Notes: Results are based on regressions using the data from the 2001, 2004, and 2008 SIPP. The sample size is 109,786 . All models include state and year fixed effects. Additional covariates are age (indicator variables for individual years), gender, race/ethnicity (white, black, Hispanic, other), child health status (5 categories), family income as a percentage of the Federal poverty level, family income squared, parent's education (4 categories), the number of children in the family, the number of months during the year that two parents were present in the household and an indicator variable for children who were uninsured for the entire year.

Robust standard errors are in parentheses.

$* p \leq 0.10 ; * p \leq 0.05$ 
Table 5. Regression Results: The Number of Dental Visits in the Past Year
(1)
(2)
(3)
(4)

\begin{tabular}{llccc} 
Billing code: & $\begin{array}{c}\text { D0150 } \\
\text { Comp. oral } \\
\text { exam } \\
\mathbf{( \$ 2 0 0 6 )}\end{array}$ & $\begin{array}{c}\text { D1120 } \\
\text { Child } \\
\text { prophylaxis } \\
\mathbf{( \$ 2 0 0 6 )}\end{array}$ & $\begin{array}{c}\text { Expected } \\
\text { fee index } \\
\mathbf{( \$ 2 0 0 6 )}\end{array}$ & $\begin{array}{c}\text { Expected } \\
\text { fee index } \\
\text { (pub./priv.) }\end{array}$ \\
\hline Public insurance & $-0.2666^{* *}$ & $-0.1694^{* *}$ & $-0.3361^{* *}$ & $-0.3306^{* *}$ \\
Medicaid payment rate & $(0.0471)$ & $(0.0596)$ & $(0.0775)$ & $(0.0784)$ \\
& 0.0007 & 0.0019 & -0.0002 & -0.0002 \\
Public insurance x Medicaid payment rate & $(0.0025)$ & $(0.0032)$ & $(0.0041)$ & $(0.0021)$ \\
& $0.0047^{* *}$ & 0.0010 & $0.0072^{* *}$ & $0.0036^{* *}$ \\
\hline \hline
\end{tabular}

Notes: Results are based on regressions using the data from the 2001, 2004, and 2008 SIPP. The sample size is 109,786. All models include state and year fixed effects. Additional covariates are age (indicator variables for individual years), gender, race/ethnicity (white, black, Hispanic, other), child health status (5 categories), family income as a percentage of the Federal poverty level, family income squared, parent's education (4 categories), the number of children in the family, the number of months during the year that two parents were present in the household and an indicator variable for children who were uninsured for the entire year.

Robust standard errors are in parentheses.

$* p \leq 0.10 ; * p \leq 0.05$ 
Table 6. Regression Results: Probability of Receiving Dental Sealants

(1)
(2)

(3)

(4)

\begin{tabular}{lcccc} 
Billing code: & $\begin{array}{c}\text { D0150 } \\
\text { Comp. } \\
\text { oral exam } \\
\mathbf{( \$ 2 0 0 6 )}\end{array}$ & $\begin{array}{c}\text { D1351 } \\
\text { Dental } \\
\text { sealants } \\
\mathbf{( \$ 2 0 0 6 )}\end{array}$ & $\begin{array}{c}\text { Expected } \\
\text { fee index } \\
\mathbf{( \$ 2 0 0 6 )}\end{array}$ & $\begin{array}{c}\text { Expected } \\
\text { fee index } \\
\text { (pub./priv.) }\end{array}$ \\
\hline Public insurance & $-0.0502^{* *}$ & -0.0147 & $-0.0454^{* *}$ & $-0.0412^{* *}$ \\
& $(0.0107)$ & $(0.0161)$ & $(0.0194)$ & $(0.0168)$ \\
Medicaid payment rate & 0.00002 & 0.0010 & 0.0003 & 0.0002 \\
& $(0.0003)$ & $(0.0006)$ & $(0.0006)$ & $(0.0003)$ \\
Public insurance x Medicaid payment rate & $0.0015^{* *}$ & 0.0002 & $0.0013^{*}$ & $0.0006^{*}$ \\
& $(0.0003)$ & $(0.0006)$ & $(0.0007)$ & $(0.0003)$ \\
\hline \hline
\end{tabular}

Notes: Results are based on regressions using the data from the 2001, 2004, and 2008 SIPP. The sample size is 109,786. All models include state and year fixed effects. Additional covariates are age (indicator variables for individual years), gender, race/ethnicity (white, black, Hispanic, other), child health status (5 categories), family income as a percentage of the Federal poverty level, family income squared, parent's education (4 categories), the number of children in the family, the number of months during the year that two parents were present in the household and an indicator variable for children who were uninsured for the entire year.

Robust standard errors are in parentheses.

$* p \leq 0.10 ; * * \leq 0.05$ 
Table 7. The Percent of Children on Medicaid receiving Dental Treatment: State-Level Analysis

\begin{tabular}{ccccc}
\hline \hline Billing code: & $\begin{array}{c}\text { D0120 } \\
\text { Standard } \\
\text { oral exam } \\
\mathbf{( \$ 2 0 0 6 )}\end{array}$ & $\begin{array}{c}\text { D0150 } \\
\text { Compr. } \\
\text { oral exam } \\
\mathbf{( \$ 2 0 0 6 )}\end{array}$ & $\begin{array}{c}\text { D1120 } \\
\text { Child } \\
\text { prophylaxis } \\
\mathbf{( \$ 2 0 0 6 )}\end{array}$ & $\begin{array}{c}\text { Expected } \\
\text { fee } \\
\text { index } \\
\mathbf{( \$ 2 0 0 6 )}\end{array}$ \\
\hline A. Percent with any dental treatment & & & & \\
Medicaid payment rate & $0.0026^{* *}$ & $0.0017^{* *}$ & 0.0010 & $0.0020^{* *}$ \\
& $(0.0010)$ & $(0.0005)$ & $(0.0008)$ & $(0.0007)$ \\
B. Percent with preventive treatment & & & & \\
Medicaid payment rate & & & & \\
& $0.0021^{*}$ & $0.0014^{* *}$ & $0.0012^{*}$ & $0.0019^{* *}$ \\
& $(0.0011)$ & $(0.0006)$ & $(0.0007)$ & $(0.0009)$
\end{tabular}

Notes: Annual state-level data are from CMS form 416 for the years 1999 to 2009 . The sample size is 528. Observations are weighted by total state population. All regressions include state and year fixed effects and the following covariates: state median income; percent of state population that is Black, Hispanic, and Asian; state unemployment rate. Standard errors are in parentheses.

$* p \leq 0.10 ; * * p \leq 0.05$ 
Table 8. ADA Survey of Dental Practice Summary Statistics

\begin{tabular}{lcc}
\hline \hline & & \\
& Mean & St. Deviation \\
\hline Accepts Medicaid $(0,1)$ & 0.381 & 0.486 \\
Percent of patients with public insurance & 6.3 & 14.670 \\
General Practitioner $(0,1)$ & 0.561 & 0.496 \\
Practice has multiple locations $(0,1)$ & 0.147 & 0.354 \\
2 to 4 dentists in practice $(0,1)$ & 0.329 & 0.470 \\
5 or more dentists in practice $(0,1)$ & 0.044 & 0.205 \\
Number of dentists missing $(0,1)$ & 0.003 & 0.056 \\
Percent of patients $<18$ years old & 27.418 & 27.408 \\
Percent of patients $<18$ missing $(0,1)$ & 0.087 & 0.282 \\
\hline \hline
\end{tabular}

Notes: Data are from the American Dental Association's annual Survey of Dental Practice for the years 1999 to 2009 . The sample size is 21,589 . 
Table 9. The Effect of Medicaid Payment Rates on Dentist Participation in Medicaid

\begin{tabular}{lcccc} 
Billing code: & D0120 & D0150 & D1120 & \\
& $\begin{array}{c}\text { Standard } \\
\text { oral exam } \\
(\$ 2006)\end{array}$ & $\begin{array}{c}\text { Compr. } \\
\text { oral exam } \\
(\$ 2006)\end{array}$ & $\begin{array}{c}\text { Child } \\
\text { prophylaxis } \\
(\$ 2006)\end{array}$ & $\begin{array}{c}\text { Expected } \\
\text { fee index } \\
(\$ 2006)\end{array}$ \\
\hline
\end{tabular}

\section{A. Any Public Patients $(0,1)$}

Medicaid payment rate

$\begin{array}{llll}0.0029^{* *} & 0.0015^{* *} & 0.0026^{* *} & 0.0031^{* *} \\ (0.0010) & (0.0006) & (0.0006) & (0.0008)\end{array}$

Implied elasticity $\quad 0.149 \quad 0.097 \quad 0.188 \quad 0.208$

\section{B. Percent Public Patients}

Medicaid payment rate

$\begin{array}{cccc}0.0417 & 0.0320^{*} & 0.0592 * * & 0.0568^{* *} \\ (0.0332) & (0.0185) & (0.0195) & (0.0252)\end{array}$

Implied elasticity

0.127

0.124

0.258

0.229

Notes: Results are based on regressions using the ADA's annual survey of dental practice data from 1999 to 2009. The sample size is 21,589. All regressions include state and year fixed effects. Additional covariates are: indicators for whether the dentist is a general practitioner, whether the practice has multiple locations, the number of dentists in the practice (4 categories including the omitted category); and the percent of the practice's patients that are less than 18 years old. Robust standard errors are in parentheses.

$* p \leq 0.10 ; * * p \leq 0.05$ 
Appendix

Table A1: Full Regression Results: SIPP Analyses

\begin{tabular}{|c|c|c|c|}
\hline & (1) & (2) & (3) \\
\hline Outcon & $\geq 1$ visit/year) & \# Visits & $\operatorname{Pr}($ Sealants $)$ \\
\hline Public insurance & $\begin{array}{l}-0.111 \\
(0.023)^{* *}\end{array}$ & $\begin{array}{l}-0.336 \\
(0.077)^{* *}\end{array}$ & $\begin{array}{l}-0.045 \\
(0.019)^{* *}\end{array}$ \\
\hline $\begin{array}{l}\text { Medicaid payment rate } \\
\text { (expected fee index \$2006) }\end{array}$ & $\begin{array}{l}-0.001 \\
(0.001)\end{array}$ & $\begin{array}{l}-0.0002 \\
(0.004)\end{array}$ & $\begin{array}{c}0.0003 \\
(0.0006)\end{array}$ \\
\hline $\begin{array}{l}\text { Public insurance } \times \text { Medicaid } \\
\text { payment rate }\end{array}$ & $\begin{array}{l}0.003 \\
(0.001)^{* *}\end{array}$ & $\begin{array}{l}0.007 \\
(0.003)^{* *}\end{array}$ & $\begin{array}{l}0.001 \\
(0.0007)^{*}\end{array}$ \\
\hline Male & $\begin{array}{l}-0.010 \\
(0.003)^{* *}\end{array}$ & $\begin{array}{l}-0.098 \\
(0.015)^{* *}\end{array}$ & $\begin{array}{l}-0.013 \\
(0.003)^{* *}\end{array}$ \\
\hline Black & $\begin{array}{l}-0.045 \\
(0.007)^{* *}\end{array}$ & $\begin{array}{l}-0.285 \\
(0.022)^{* *}\end{array}$ & $\begin{array}{l}-0.058 \\
(0.005)^{* *}\end{array}$ \\
\hline Hispanic & $\begin{array}{l}-0.034 \\
(0.007)^{* *}\end{array}$ & $\begin{array}{l}-0.178 \\
(0.028)^{* *}\end{array}$ & $\begin{array}{l}-0.023 \\
(0.006)^{* *}\end{array}$ \\
\hline Other race/ethnicity & $\begin{array}{l}-0.072 \\
(0.008) * *\end{array}$ & $\begin{array}{l}-0.214 \\
(0.031)^{* *}\end{array}$ & $\begin{array}{l}-0.044 \\
(0.008)^{* *}\end{array}$ \\
\hline Parent high school graduate & $\begin{array}{l}0.060 \\
(0.009)^{* *}\end{array}$ & $\begin{array}{l}0.094 \\
(0.029)^{* *}\end{array}$ & $\begin{array}{l}0.019 \\
(0.006)^{* *}\end{array}$ \\
\hline Parent has some college & $\begin{array}{l}0.126 \\
(0.010)^{* *}\end{array}$ & $\begin{array}{l}0.303 \\
(0.032)^{* *}\end{array}$ & $\begin{array}{l}0.060 \\
(0.006)^{* *}\end{array}$ \\
\hline Parent has college degree & $\begin{array}{l}0.173 \\
(0.011)^{* *}\end{array}$ & $\begin{array}{l}0.379 \\
(0.036)^{* *}\end{array}$ & $\begin{array}{l}0.088 \\
(0.007)^{* *}\end{array}$ \\
\hline Age 3 & $\begin{array}{l}-0.319 \\
(0.008)^{* *}\end{array}$ & $\begin{array}{l}-1.344 \\
(0.038)^{* *}\end{array}$ & $\begin{array}{l}0.065 \\
(0.004)^{* *}\end{array}$ \\
\hline Age 4 & $\begin{array}{l}-0.180 \\
(0.007)^{* *}\end{array}$ & $\begin{array}{l}-1.041 \\
(0.037)^{* *}\end{array}$ & $\begin{array}{l}0.100 \\
(0.005)^{* *}\end{array}$ \\
\hline Age 5 & $\begin{array}{l}-0.090 \\
(0.007)^{* *}\end{array}$ & $\begin{array}{l}-0.803 \\
(0.040)^{* *}\end{array}$ & $\begin{array}{l}0.149 \\
(0.005)^{* *}\end{array}$ \\
\hline Age 6 & $\begin{array}{l}-0.063 \\
(0.007)^{* *}\end{array}$ & $\begin{array}{l}-0.703 \\
(0.038)^{* *}\end{array}$ & $\begin{array}{l}0.206 \\
(0.006)^{* *}\end{array}$ \\
\hline Age 7 & $\begin{array}{l}-0.041 \\
(0.007)^{* *}\end{array}$ & $\begin{array}{l}-0.603 \\
(0.038)^{* *}\end{array}$ & $\begin{array}{l}0.282 \\
(0.007)^{* *}\end{array}$ \\
\hline Age 8 & $\begin{array}{l}-0.028 \\
(0.006) * *\end{array}$ & $\begin{array}{l}-0.527 \\
(0.039)^{* *}\end{array}$ & $\begin{array}{c}0.321 \\
(0.008)^{* *}\end{array}$ \\
\hline Age 9 & $\begin{array}{l}-0.040 \\
(0.006)^{* *}\end{array}$ & $\begin{array}{l}-0.501 \\
(0.038)^{* *}\end{array}$ & $\begin{array}{c}0.338 \\
(0.008)^{* *}\end{array}$ \\
\hline Age10 & $\begin{array}{l}-0.032 \\
(0.006)^{* *}\end{array}$ & $\begin{array}{l}-0.419 \\
(0.040)^{* *}\end{array}$ & $\begin{array}{c}0.343 \\
(0.008)^{* *}\end{array}$ \\
\hline Age 11 & $\begin{array}{l}-0.040 \\
(0.006)^{* *}\end{array}$ & $\begin{array}{l}-0.333 \\
(0.041)^{* *}\end{array}$ & $\begin{array}{l}0.348 \\
(0.008)^{* *}\end{array}$ \\
\hline Age 12 & $\begin{array}{l}-0.043 \\
(0.006)^{* *}\end{array}$ & $\begin{array}{l}-0.105 \\
(0.046)^{* *}\end{array}$ & $\begin{array}{l}0.339 \\
(0.008)^{* *}\end{array}$ \\
\hline Age 13 & $\begin{array}{l}-0.055 \\
(0.006)^{* *}\end{array}$ & $\begin{array}{c}0.043 \\
(0.047)^{* *}\end{array}$ & $\begin{array}{c}0.339 \\
(0.008)^{* *}\end{array}$ \\
\hline Age 14 & $\begin{array}{l}-0.083 \\
(0.007)^{* *}\end{array}$ & $\begin{array}{l}-0.029 \\
(0.047)^{* *}\end{array}$ & $\begin{array}{c}0.313 \\
(0.009)^{* *}\end{array}$ \\
\hline
\end{tabular}




\begin{tabular}{llll} 
Health is Very Good & -0.027 & -0.077 & -0.014 \\
& $(0.005)^{* *}$ & $(0.020)^{* *}$ & $(0.004)^{* *}$ \\
Health is Good & -0.037 & -0.053 & -0.019 \\
& $(0.006)^{* *}$ & $(0.025)^{* *}$ & $(0.005)^{* *}$ \\
Health is Fair & -0.005 & 0.099 & 0.002 \\
& $(0.012)$ & $(0.061)$ & $(0.011)$ \\
Health is Poor & 0.008 & 0.385 & -0.012 \\
& $(0.033)$ & $(0.236)$ & $(0.025)$ \\
Number $<18$ in family & -0.004 & -0.043 & 0.004 \\
& $(0.002)$ & $(0.007)^{* *}$ & $(0.002)^{* *}$ \\
Months with two parents & -0.0004 & -0.001 & 0.0002 \\
& $(0.0004)$ & $(0.002)$ & $(0.0003)$ \\
Avg. income (pct. of pov.) & 0.0001 & 0.001 & 0.0001 \\
& $(0.00001)^{* *}$ & $(0.0001)^{* *}$ & $(0.00001)^{* *}$ \\
Avg. income squared/10000 & -0.0001 & -0.0005 & -0.00005 \\
& $(0.00003)^{* *}$ & $(0.0001)^{* *}$ & $(0.00002)^{* *}$ \\
Full year uninsured & -0.301 & -0.759 & -0.111 \\
& $(0.009)^{* *}$ & $(0.031)^{* *}$ & $(0.006)^{* *}$ \\
Constant & 0.646 & 1.490 & -0.122 \\
& $(0.042)^{* *}$ & $(0.262)^{* *}$ & $(0.025)^{* *}$ \\
$R^{2}$ & 0.12 & 0.07 & \\
\hline
\end{tabular}

Notes: Results are based on regressions using the data from the 2001, 2004, and 2008 SIPP. The sample size is 109,786 . All models also include state and year fixed effects.

Robust standard errors are in parentheses.

$* p<0.05 ; * * p<0.01$ 
Table A2. Full Results: ADA-SDP Analyses

\begin{tabular}{lcc}
\hline \hline \multicolumn{1}{c}{ Dependent Variable: } & $\begin{array}{c}\text { Any Publicly Insured } \\
\text { Patients (0,1) }\end{array}$ & $\begin{array}{c}\text { Public Insurance as a } \\
\text { Percent of All Patients }\end{array}$ \\
\hline Medicaid Fee Index & 0.0030 & 0.0568 \\
& $(0.0008)$ & $(0.0251)$ \\
General Practitioner $(0,1)$ & 0.0677 & 3.1962 \\
& $(0.0090)$ & $(0.3109)$ \\
Practice has multiple locations $(0,1)$ & 0.0629 & 1.1010 \\
& $(0.0111)$ & $(0.3761)$ \\
2 to 4 dentists in practice $(0,1)$ & 0.0522 & 1.1964 \\
& $(0.0070)$ & $(0.2204)$ \\
5 or more dentists in practice $(0,1)$ & 0.1461 & 6.8646 \\
& $(0.0160)$ & $(0.7313)$ \\
Number of dentists missing $(0,1)$ & 0.2724 & 13.2769 \\
& $(0.0472)$ & $(3.1870)$ \\
Percent of patients $<18$ years old & 0.0035 & 0.1565 \\
& $(0.0001)$ & $(0.0061)$ \\
Percent of patients $<18$ missing $(0,1)$ & -0.0390 & -1.0361 \\
& $(0.0115)$ & $(0.3617)$ \\
\hline $\mathrm{R}^{2}$ & 0.119 & 0.116 \\
\hline \hline
\end{tabular}

Notes: Results are based on regressions using the ADA's annual survey of dental practice data from 1999 to 2009. The sample size is 21,589. All regressions include state and year fixed effects. Robust standard errors are in parentheses. 